\title{
Male Survivor Perceptions of Seeking Support: Hermeneutic Analysis of a Cluster Case Study
}

\author{
Joseph Lumbasi \\ University of Dundee, Scotland
}

Ian Barron

University of Dundee, Scotland

E-mail: i.g.z.barron@dundee.ac.uk

\author{
Received: November 24, 2015 Accepted: April 5, 2016 Published: May 3, 2016 \\ doi:10.5296/ijsw.v3i1.8626 URL: http://dx.doi.org/10.5296/ijsw.v3i1.8626
}

\begin{abstract}
Studies with male survivors of child sexual abuse (CSA) are limited in focus and only one study, to date, has explored survivor perceptions of sexual assault treatment services. The current study, sought to deepen the understanding of survivor experience by identifying the triggers and barriers for seeking support as well as how survivors overcome these barriers. A cluster case study design was used with three adult males. A hermeneutic analysis was utilized to identify and explore meanings from male survivor perspectives. The study found male survivors dealt with barriers to support, through a range of strategies, including adopting helping others, rather than seeking sexual assault treatment services. Hermeneutic analysis was identified as an empowering process that enabled male survivors express their experiences. Large scale studies are needed to explore the potential wide range of male survivor experience.
\end{abstract}

Keywords: child sexual abuse, masculinity, qualitative research, support services

1. Male Survivor Perceptions of Seeking Support: Hermeneutic Analysis of a Cluster Case Study

Most studies of child sexual abuse (CSA) in males have tended to focus on: the nature and extent of abuse (Easton, 2014; Easton, Renner, Lynette, \& O'Leary, 2013); the long term consequences (Pérez-Fuentes et al., 2013; Easton, 2014; Easton, Coohey, Rhodes, \& Moorthy, 2013; Sigurdardottir, Halldorsdottir, \& Bender, 2012; MacMillan et al., 2001); who the perpetrators are (Holmes, 2007; Grossman, Sorsoli, \& Kia-Keating, 2006; Kia-Keating et al., 
2005); and one study, to date, explored male survivor experiences of sexual assault treatment services (Du Mont et al., 2013). Du Mont and colleagues in a descriptive exploratory study of male survivors' use of sexual assault treatment services found out that $85 \%$ utilized those related to health care on-site such as crisis counselling, treatment of injuries and referral for follow up counselling; however, findings were limited to sexual assault. Studies into support services for male survivors of CSA are therefore rare and tend to be gendered towards women's needs (Nelson, 2009). This is perhaps not surprising, as prevalence rates suggest females are significantly more at risk than males (Finkelhor, Turner, Shattuck, \& Hamby, 2013; Laaksonen et al., 2011; Perez-Fuentes et al., 2013). Male survivors are further marginalized, as they are often referred to female support services based on an unquestioned assumption of the similarity between male and female survivor support needs (Hooper \& Warwick, 2006).

Support for survivors, in this study was defined in its widest sense. Support can come from family, peers, voluntary and statutory agencies and can involve tasks and activities which are formal and informal as well as implicit and explicit (Nelson, 2009). Support can be emotional, social and cognitive, medical and financial. Studies into seeking support suggest males tend to avoid services until something major occurs in their lives (Broadhurst, 2003). Examples of major events include experiencing grief due to loss of a loved one or having to appear in court for an offence (O'Leary \& Gould, 2009). Theories of masculinity have sought to explain support avoidant behavior, as men maintaining a cultural 'stiff upper lip' at times of emotional stress (Bennett, 2007). Specifically in relation to CSA, Matthew (2002) observed that males are more likely to seek support services for presenting symptoms such as depression or anxiety rather than for the abuse itself.

Avoidance of support by males may in part be due to a belief that disclosing feelings is seen as a sign of weakness for men. The admission of problems can be interpreted as incompetence and seeking support from others construed as simulating a feminine personality trait (Garfield, Isacco, \& Rogers, 2008). Males, as western culture emphasizes, are supposed to be able to protect themselves (Easton, 2014; Easton, Saltzman, \& Willis, 2014; Holmes, 2007; Kia-Keating et al., 2005). Even more undermining of seeking support, is the gender stereotype of males as sexually aggressive. This in turn, can make it difficult for males to be seen as the victim of a sexual assault (Easton, 2014; Mein, et al., 2003). Teram, Stalker, Hovey, Schachter, \& Lasiuk (2006) argue that (i) the internalization of societal stereotypes and (ii) the marginalization of male victimization create barriers that make it difficult for males to take the first step in seeking support. As a result of avoiding support, males can experience the long term consequences of unresolved abuse. Symptoms include depression, anxiety, suicidal ideation, self-harm, relationship difficulties, sexual dysfunction and substance misuse (Paine \& Hansen, 2002). By asking men about their experiences of seeking help and the barriers they encountered, this study aims to discover whether these theoretical assertions have an empirical base.

Closely associated with the avoidance of support is the avoidance of disclosing abuse. Alaggia and Millington (2005) interviewed eleven male survivors of CSA and found several barriers to male disclosure. Males reported they feared being viewed as homosexual, a victim, or an abuser. The authors concluded that "for men, being sexually abused by a male evokes unique 


\section{MInstitute Macrothink $^{\text {Int }}$}

conflicts about their sexuality and sexual orientation; men are strongly affected by prevailing attitudes about masculinity and what it means to be a man in a patriarchal, heterosexist society" (p. 464). On the other hand, abuse by females can lead to confusion of who was in control, who wanted the abuse and of not enjoying sexual activity. Men are assumed to always enjoy the latter. All these factors make it difficult for males to acknowledge abuse and subsequently disclose (Easton, 2014; Easton, Saltzman, \& Willis, 2014; Kia-Keating et al., 2005).

The socialization of masculinity not only leads to avoidance of support and disclosure but also lead to the denial of men as victims within the social contexts they inhabit (Emslie, Damian, Ziebland \& Hunt, 2006). When societal myths about masculinity are held by family members, caretakers and agencies, external barriers are created for survivors to disclose to those they are supposed to trust. During childhood, for example, parents may be less vigilant in monitoring or detecting problems following the victimization of boys (Spataro, Moss, \& Wells, 2001). Officials, such as, child protection workers, can also subscribe to beliefs that minimize the prevalence or negative effects of CSA for men (Spataro, Moss \& Wells, 2001). These beliefs can make officials less likely to substantiate cases of CSA involving men as victims (Easton, Saltzman, \& Willis, 2014; Easton, 2014; Holmes, 2007; Kia-Keating et al., 2005) as well as undermine the delivery of services to male survivors and their families (Agar \& Read, 2002). Clinicians may also hold similar biases that hinder identification, assessment, and treatment of CSA in male clients (Easton, Saltzman, \& Willis, 2014; Easton, 2014; Holmes, 2007). These institutional barriers can all thwart disclosure of CSA for males. Beyond institutions to community, Neame \& Heenan (2003), highlight that male survivors may be reluctant to disclose because of community assumptions that have often labelled male survivors as future perpetrators, homosexuals, liars, and emotionally weak. As a consequence, male survivors can live in fear of being treated as social outcasts.

The denial of male CSA by society is mirrored in the limited number of studies concerned with male survivor issues. Studies into the prevalence of CSA in males are considerably less than female studies. From studies that have been conducted, estimates range from 3 to $31 \%$ of the male population who may have experienced CSA (Finkelhor, Turner, Shattuck, \& Hamby, 2013; Perez-Fuentes et al., 2013). Prevalence statistics suggest that four times as many girls are abused as boys. However, as awareness of female perpetration grows, a corresponding awareness of males experiencing CSA also increases (Finkelhor, Turner, Shattuck, \& Hamby, 2013; Easton, 2014). As with girls, perpetrators are mostly known to the victim and perpetrators can be multiple in number. A high risk of onset of abuse occurs around age ten, however abuse of boys can occur at any age (Easton, 2014; Holmes, 2007; Kia-Keating et al., 2005). Because of the nature of male under-reporting it is difficult to estimate the actual levels of male CSA.

In response to the absence of research into male survivor support seeking behavior, the current study explores male survivor perceptions of what leads males to seek support, what barriers they experienced in doing so and how they overcame these barriers. A qualitative cluster case study design was selected because of its real-world focus, the importance it can give to survivor experience and voice, and the enhanced validity and extendability of findings that comes from analysis of repeated cases (Galloway \& Sheridan, 1994; Yin, 2013). As 
Meyer (2001) states, a cluster case study design allows for rich descriptions, deeper understandings and a more fully nuanced view than would be possible in a single case study.

Within the cluster case study, a hermeneutic approach is taken to analysis. Hermeneutics is based on the assumption that survivors give meaning to what has happened in their lives and that this meaning can be expressed in different ways (Preininger \& Rapmund, 2008). Hermeneutic analysis has been used to explore the thoughts and feelings of vulnerable populations with sensitive issues such as mental health, drug misuse and long term illnesses (Fleming, Gaidys, \& Robb, 2003). The value of hermeneutic analysis is that it provides a process of enabling the expression and interpretation of unique accounts from vulnerable populations often omitted in research studies. In the search for unique participant meanings, hermeneutics provides a systematic approach to analyze verbal, non-verbal and para-verbal communication. The limitations of such an approach are discussed following the analysis of male survivor accounts.

\section{Methods}

\subsection{Ethics}

The study was approved through the University of Dundee Research Ethics committee. Participants were provided with information in order to make an active informed decision of involvement. Information was provided on the two researchers. One was a practitioner in an abuse survivor organization, the other, an educational psychologist who had worked with survivor organizations for over 10 years. Information was provided on the aims and expectations of the study; the role and contribution of participants, interview procedures, rules on confidentiality, information about data protection and the right of participants to withdraw at any time. As a vulnerable population, participants were protected from distress and regret by offering them contact details of abuse support services that would help them. We also made a follow up with the participants through telephone and email to ascertain that they had not suffered any distress in the process of participating in our research.

\subsection{Participant Sampling}

Using purposive and voluntary sampling, the small number of male survivor agencies in Scotland $(n=3)$ were approached to facilitate recruitment of participants. An email was then sent to survivors, introducing them to the researchers and asking them to make contact if they were interested in participating in the study. Three adult male survivors of CSA self-referred and were selected as a cluster case study (McClintock, Brannon, \& Maynard-Moody, 1979; Yin, 2013). The male survivors were identified through abuse support agencies offering services to male survivors in two cities and one town in Scotland. All the participants met the criteria of being male, over 18 years old, had experienced sexual abuse in childhood and volunteered for the study.

Throughout the study, the three men are referred to Mr. X, Mr. Y and Mr. Z. All men were middle aged: $X=45$ years; $Y=48$ years and $Z=52$ years. $M r . Z$ was in stable employment, but at the time of interview was moving into a counselling career. The other two men (Mr. Y and Mr. X) were unemployed. Mr. X cited ill health and Mr. Y saying he just needed a break. Mr. Y had previously worked in both professional and manual jobs. All men had college and university education of at least three years. Mr. Y and Mr. Z were in stable relationships 
(married for over 20 years), while Mr. X was divorced. Mr. X and Mr. Y were fathers with the former having one child and the latter two. Mr. $\mathrm{Z}$ did not have children. All were Caucasian. Mr. X and Mr. Y were receiving disability allowance. Mr. X had a back injury and mental health problems and Mr. Y had a history of physical health difficulties.

\subsection{Interviews}

Interviews were designed to facilitate hermeneutic analysis. Questions focused on enabling participants to share their experiences and what this meant for them. Initial questions were simple and concrete to enable participants to experience success and confidence and facilitated the process of talking about sensitive topics such as CSA. The researcher responded with affirming nods, asking for clarification and summarizing what had been said to check understanding. Questions covered demographic information (age, marital status, location, ethnicity, employment); life history (social, education, employment, religion and health trajectories); abuse characteristics (definitions and age of onset); support-seeking behavior (when first sought support; what triggered seeking support) barriers to seeking support (barriers then when first sought support, barriers now to seeking support, how barriers were overcome); the nature of support (current and past types of support, formal/informal supports, adequacy of supports); what needs to be considered in supporting male survivors; and a request for any further comments. Prompts, where necessary, involved asking survivors what these experiences meant for them.

\subsection{Procedures}

Since, an objective of hermeneutic research is to collect data in a setting that is empowering (Blanche, Durheim, \& Painter, 2008), participants were given the choice of place of interview. Interviews with $\mathrm{X}$ and $\mathrm{Y}$ took place in their homes, while the interviews with $\mathrm{Z}$ took place in a survivor organization office. Interviews occurred over two sessions on average lasting two hours each. Interviews were delivered in a conversational style and recorded using an audio digital recorder.

\section{Analysis}

Interview data was analyzed using hermeneutics in order to seek to understand the meaning participants gave to their experience of seeking support. Analysis of the transcribed conversations followed the hermeneutic convention of moving from the whole transcript to part of the transcript and then returning to the whole again (Gadamer, 1991). The process of analysis involved five steps, i.e. familiarization and immersion; thematizing; interpretation; elaboration; and checking. At the familiarization and immersion phase, interviews were read to obtain an overall understanding. Thematizing involved writing a summary of each interview $(n=3)$ and common themes (meanings) being identified. Interpretation involved each survivor statement being analyzed to reveal its meaning relative to the identified themes. Transcripts were then examined to find quotations that reflected the fundamental meaning of the conversation. It is important to recognize, the themes identified were representative of the researchers' understandings of participant statements. In order to provide an authentic account of the male survivor meanings, where possible, male survivors' own words are used in the results and discussion.

The elaboration phase involved (i) a review of identified themes that emerged from sentence 
by sentence analysis, (ii) comparing these themes with the summaries and (iii) identifying salient quotes. This led to adaptation and development of further themes. Checking involved a final read through and consideration of the interpretation of text and presentation of various themes. In order to provide a more accessible and meaningful experience for the reader, excerpts from transcripts are woven into researcher interpretation in order to make visible the connection between data and meanings.

\section{Reliability of Analysis}

The use of direct quotes from the text allows the reader to judge the information provided. This is what Lincoln \& Guba (1985) termed an "audit trail", by which a third party can reach conclusions based on the data. In addition, inter-rater reliability involved two researchers independently analyzing the data. The analysis of data was also discussed on three occasions with the three male participants. Participants were given the opportunity to ask questions about the interpretation of their data and contribute additional perspectives on transcripts and themes.

\section{Results}

Comparison of the analysis of the data by the two researchers indicated a high level of commonality of interpretation. There was however a difference in terms of the themes some of the quotes were listed under. Quotes therefore, did not always fit neatly within one theme. Male survivor comments on researcher interpretation indicated survivors wished more emphasis on the personal impact for survivors, of the lack of services' awareness of male survivor issues. Further, participants wanted more of a focus on what needs to be changed in support services' attitudes.

\subsection{Seeking Support}

The three participants reported that something "drastic" needed to happen to trigger their support seeking behavior: "the first time I went seeking for help, was when I was 48 years and it was not support for the abuse or anything to do with alcohol, what I sought support with was the woman who I had loved died and I had huge grief, so I went into counselling for grief” (Mr. Z.); "at 33 years I basically went for counselling because I was struggling, I had seen the guy who had abused me, I had seen that person with a young child in a car park and that again just triggered me, I had to report to the police" (Mr. X.); "I never sought any support until he was charged and that time I was 32, I went to the GP because I needed a referral to a counsellor, I knew there were psychiatrists but I never thought I had mental health problems, of course I knew I had anxiety problems due to the court case coming up but I never thought I needed such services" (Mr. Y.).

Support seeking behavior for these male survivors tended to be triggered by significant events and resultant behavioral, emotional and physical problems. A wide range of triggers for seeking support were reported. These included an upcoming court case of an abuser, alcohol problems, domestic violence, grief due to bereavement, aggression, anger management, sexual disturbance and ambivalence, self-harming, attempted suicide and the subsequent disclosure of abuse by a close relative. An unexpected trigger for seeking support, however, was the male desire "to turn something negative into a positive". All three survivors reported this as a motivating factor. 


\subsection{Barriers}

Participant statements indicated that most delayed seeking support for sexual abuse over many years. Mr. Z., for example, stated that even after eventually going for counselling, the issue of CSA did not come up until " 4 months into counselling". A range of internal and external barriers were identified that hindered men. A major internal barrier was reported as their inability to legitimize what they had suffered abuse as children. Mr. Z. reported "I was in a state of confusion, self-blame, denial and unable to legitimize my experience as abuse because my body was telling me that this is good, but I knew it was wrong, and again my abuser did not pull me or force me, or snatch me from the streets, I just walked into his trap and kept going back".

The inability to access thoughts and feelings due to blocked childhood memories and denial of abuse also appears to have been a barrier to seeking support: "I did unfortunately develop an attitude that you can't help me because I have been hurt because of the sexual abuse that happened to me, I had recoiled into myself and built up defense barriers, so that I did not think about it, I started self-harming" (Mr. X.). This was further compounded with the inability to tell someone about abuse due to shame: "I had been obviously ashamed of it, embarrassed feeling that should I have said it to somebody, or shouldn't I have said to somebody ... what would have happened ... just trying to forget about it" (Mr. Y.). "But what I couldn't do even the next week in the session was accessing any of the emotions, I recounted exactly what had happened and there wasn't a shred of emotion and it still did not occur to me that I cannot access the emotions"(Mr. Z.).

Blocked memories and the inability to access emotions, appear to have undermined participant ability to be aware of their support needs and as a result hindered them from support-seeking. Mr. Z. reported "because it is not until I have recognized a need, that I have actually sought a response for that need because largely what the abuse did to me, it removed my awareness of needs, I did not need anything, I can be absolutely self-sufficient and I spent 40 years like that and I did not know what my needs were".

External barriers were also reported as getting in the way of participants seeking support. These barriers were reported as pervasive in nature. Regardless of whether abuse was within and/or beyond the family, lack of support was reported from family members, caretakers, adults in positions of authority, professionals and abuse support agencies. Mr. Y. reported he lacked support from his mother "because he was abused within the family by his father". Mr. Z. reported that because "My father was unstable, on reflection he was suffering from some form of untreated dissociation, he was verbally incredibly abusive not so much physically but emotionally and verbally abusive to my mum and me." This acted as a barrier to him telling about the CSA he suffered from an elderly neighbor. Mr. X. on the other hand was let down by his ex-partner who used CSA as a weapon, i.e. she accused him of being a pedophile to deny him access to his daughter: "Like if I hadn't told my daughter's mother about my sexual abuse, she wouldn't have made such allegations to social services, which went to my daughters' medical records, which is a form of domestic abuse, implying that since I was sexually abused".

Another external barrier experienced by the three participants was professionals who lacked knowledge and skills on how to support adult male survivors. For example, Mr. Y. remembers 
the first time he went to his GP to seek support ... "and I flicked to page 14 (of the court transcript) which starts to talk about sexual abuse and I was really nervous and told him can you look at this, he took his time and he said, oh yes, family abuse, he then looked up over his glasses at me and asked me, how is your mother? And I just thought, what? I am not here for my mother? I told him I am just needing a counsellor, to help me get through the court case, but it is like he was not listening because he just told me you need to put this behind you".

Bias and lack of dedicated support services for male survivors were other identifiable barriers. Services were described as "mostly for women"; the court system was reported as "daunting"; child protection hearings as "biased" and participants felt "blamed as being potential abusers" $(n=3)$. Poor referral mechanisms for males to access immediate support led to the experience of seeking help as "arduous". Survivors were subjected to "much probing, questioning and risk assessment". Furthermore, limiting support and counselling services to 12 week sessions was perceived as insufficient to enable survivors overcome their internal barriers and "blocked memories of over 30 years".

\subsection{Overcoming Barriers}

A major strategy used by all three participants was turning the negative associated with self-harming, anger, shame, embarrassment, and denial into "positive energy". For example, "I did actually find a way of channeling my aggression to martial arts, scuba, judo, I did a lot of weight lifting" (Mr. X.); "I write, I draw, I paint, anything that I need to do to access what is going on inside me, I will work it, I will read, I will study, I will meditate, I will do anything to access my feelings" (Mr. Z.); "We can turn this negative into positive and that is why I have been very much involved in speaking at conferences, volunteering, teaching something, writing poems, creating songs and spiritual nurture” (Mr. Y.). Survivors responses on overcoming external barriers, suggests a need for a multi-layered approach involving family, society and agencies, "there is need for more emphasis to involve charities to pull together and work towards support, smaller charities need to form into a beehive, network in the effort to support survivors, organizations need to work together, awareness needs to be made with hospital emergency departments so that when people come in, they meet staff who are well trained in mental health issues" (Mr. X.).

Survivors suggested that family members, support services and wider society need to empower survivors to rebuild confidence and repair trust. The following quotes highlight the importance survivors put on developing accessible and responsive services: "Support services need to help survivors be able to understand their inner feelings and emotions but support services need not make survivors depend on their services, they need to make survivors more dependent on themselves and that is what support services need to do, they should not turn support services into businesses" (Mr. Y.). Survivors reported "support services should not be turned into systems with long waiting lists, complex referral mechanisms, but they need to be simplified, flexible and working at the pace of service users".

The three participants further said that there is need to "raise the profile of services for males, put literature in places that provide services for men, put contact details of services for CSA in yellow pages, put male support services in a support group to ease delays in referrals and train Accident and Emergency staff and other professionals on how to help men who come to 
their clinics with issues around self-harming" (Mr. X.).

\subsection{Research as a Route to Overcoming Barriers}

A series of spontaneous positive comments were made regarding participants' involvement in research. "You are empowering people to change their approach to life and give something back, to give the information I am giving now. I am empowering someone to be able to deal with and cope and manage and improve services, which will benefit other victims" (Mr. X.). "For myself, this has been a hugely therapeutic exercise. Every now and then in my counselling we will see where we have come from and where we are, a recap process and that is what I have done today, but over the whole process and I feel that there has been a gathering together...and there is a sense of ....wauhh!... that is something...that is a piece of work....wauhh!...that is how I feel. What I was describing earlier about turning these awfulness into something positive. I feel today that I have given something out of that and that makes it worthwhile." And finally, "instead of complaining turn the shit into compost and make some good use of that compost...turn the negative shit (stuff) in to something positive...like the work we are doing now with you taking part in your research aimed at helping other men. But not writing a big university book...but turn it in to use in my own little way, because I have been the man who has been on the moon. I have the firsthand knowledge of childhood sexual abuse, so mine is firsthand experience, because I want to give something back. I want to help others."

\section{Discussion}

The current study sought to explore male survivor perception of seeking support, the barriers encountered and how survivors overcame these. As with previous studies, survivors sought support for a wide range of adversity and psychosocial difficulties, rather than CSA. Disclosure of CSA for all three men occurred once a trusting relationship had been established. Unexpectedly however, male survivors were also motivated to seek support to turn negative traumatic experiences into something positive, not only for themselves but for others. Survivor narratives on barriers, extended the key messages from previous literature (Kia-Keating, Sorsoli, \& Grossman, 2010; Easton, Saltzman, \& Willis, 2014; Easton, 2014; Willis et al., 2014) that men encounter relational, personal and socio-environmental obstacles that impede their recovery. While previous studies highlight the challenges men experience adapting in life after having suffered from childhood sexual abuse, the current study, using a cluster case study approach and hermeneutic analysis sought to understand experience of these barriers, and strategies to overcome, these through survivors' own voices.

The survivor responses in the current study indicated male survivors experienced four main types of barriers in seeking help. Firstly, intrapersonal barriers included the inability to access thoughts and feelings and lack of awareness of one's own needs. Secondly, interpersonal barriers included feelings (e.g. embarrassment, feeling dirty) in relation to their abuse and the perceived response of others, (e.g. denial, rejection, and disclosure used as a weapon), family mental health limiting disclosure and the lack of support in the family and extended family. Thirdly, community barriers included lack of professional knowledge and skills, gender bias and lack of dedicated services for men, and the arduous nature of court, hearings and intrusive assessments. Therapeutic programs offered were reported as short and viewed as superficial and invalidating. And fourthly, societal and cultural barriers included 
how men felt wider society would view and respond to them, e.g. as perpetrators or as weak or defective in some way. Of particular concern, were the myths reported to be held by support and health services. For example, when the three male survivors reluctantly came forward for support, experiences were minimized or not taken seriously. It is saddening that this pattern of service response continues, despite having been identified in earlier research (Denov, 2004). Survivor's reported resultant interpersonal responses highlighted the profound impact such barriers had on their negative sense of well-being and support-seeking behavior.

Male survivors were able to identify a wide range of strategies for themselves, their families, services (voluntary and statutory) and for society. Survivors suggested the need for a layered approach which would address both internal and external barriers and the interaction of the two. In terms of overcoming internal barriers, participant responses indicate the following supports need to be developed: opportunities for enabling men to "channel their aggression into constructive and creative activities"; the teaching and practice of "coping strategies"; "learning ways of managing emotions"; opportunities for "contributing to others understandings", such as "presenting at workshops for professionals and communities"; access to "spirituality and spiritual healing"; and opportunities for "delivering service within survivor groups". All strategies, according to survivors, need to focus on "developing survivor independence".

Externally, male survivors highlighted the need for "coordination of statutory and voluntary services"; "better informed and aware services"; "services that listen" and offer "belief in male survivor reports of abuse"; and services that are willing to hold the hypothesis that there may be "abuse underpinning problems". In addition, males want "simple referral systems" and "quick access to services". Such developments again demand attitudinal change, political will, as well as financial investment (Matthew, 2002). Specific guidelines and training for frontline statutory and voluntary staff would seem to be essential. Further, support services need to offer support not just for male survivors but also for their "families and communities in challenging myths" about males and abuse. In short, there is a need for a change in understanding, belief and a willingness to act and provide support to male survivors at interpersonal, family, community, societal, and cultural levels (Hovey, Stalker, Schachter, Teram, \& Lasiuk, 2011). Counter to such developments, however, are funding and resource issues as well as the challenge of overcoming inertia in attitudinal change at professional, organizational and societal levels (Gallo-Silver, Anderson, \& Romo, 2014).

Unexpectedly, participants included the theme that research is another potential form of support for the barriers male survivors' experience. Participant responses indicated that those who get involved in research can experience relief in having their stories heard and in helping others with their recovery (Allan, 2006). Further, rather than internalizing societies condemnation as in these participants' lives, a hermeneutic driven interview enabled survivors to disclose their experiences and give meaning to their stories for themselves and others. It may be the case that hermeneutics can be a useful method in enabling participants share experiences and their meanings for a range of other sensitive and emotive topics.

\section{Limitations}

Hermeneutics has been criticized for limited reliability and trustworthiness of analysis, because of the subjective nature of word meanings (Lincoln \& Guba, 1985). An educational 
psychologist brings a professionalized mind set and someone working in a survivor's organization may be influenced by many survivor stories. One may be overly cautious with interpretation, the other less so. The sample size was small and in a cluster case study there is always bias in the characteristics of the sample, i.e. all males were middle aged, had volunteered and had chosen to approach survivor organizations for support. This raises questions about the representativeness of the sample and the generalization of the findings. Survivors who do not seek support in survivor organizations, for example, may experience different barriers to seeking support. The study covered a narrow range of issues in relation to support seeking behavior and no attempt was made to quantify the significance of the issues raised.

\section{Conclusion}

The current study affirms, in survivors' own words, that adult males seek support when something serious threatens their mental, physical and/or psychological well-being, rather than for CSA. The three survivors in this study, however, also sought support to turn the harms they experienced into something positive for self and others. Barriers to seeking support and to subsequent disclosure were pervasive and both internal and external to the survivors. Overcoming these issues appears to be a multi-layered challenge for survivors, families, services and society. Survivors were, however, able to recommend a wide range of possible developments for future practice. The authors consider male survivor needs are sufficiently unique to warrant the provision of dedicated male survivor services. Finally, hermeneutics is a promising approach in facilitating survivor story and in discovering the unique perspective and meanings for male survivors.

\section{Recommendations for Future Research}

Future studies need to explore a broader range of potential factors for male survivors including socio-cultural barriers as well as intrapersonal factors in the avoidance of support seeking and CSA disclosure. Studies need to include larger cluster case study samples, consider quasi-qualitative approaches to systematic analysis as well as involve more active participation of survivors in the process of research, e.g. participatory action research. Hermeneutics as a process of analysis within the field of survivor experience requires further evaluation.

\section{References}

Agar, K., \& Read, J. (2002). What happens when people disclose sexual or physical abuse tostaff at a community mental health center? International Journal of Mental Health Nursing, 11, 70-79. http://dx.doi.org/10.1046/j.1440-0979.2002.00230.x

Alaggia, R., \& Mishna, F. (2014). Self-Psychology and Male Child Sexual Abuse: Healing Relational Betrayal. Clinical Social Work Journal, 42(1), 41-48. http://dx.doi.org/10.1007/s10615-013-0453-2

Alaggia, R., \& Millington, G. (2008). Male Child Sexual Abuse: A Phenomenology of Betrayal. Clinical Social Work Journal, 36, 265-275. http://dx.doi.org/10.1007/s10615-007-0144-y

Allan, L. (2006). Forgotten Victims: Impact of Childhood Sexual Abuse on Male Survivors 
(Unpublished Master's Thesis). University of Dundee.

Bennett, K. (2007). "No Sissy Stuff": Towards a theory of masculinity and emotionalexpression in older widowed men. Journal of Aging Studies, 21, 347-356. http://dx.doi.org/10.1016/j.jaging.2007.05.002

Blanche, M., Durheim, K., \& Painter, D. (2008). Research in Practice: Applied Methods for the Social Sciences (2nd Edition). Cape Town: University Press.

Broadhurst, K. (2003). Engaging parents and carers with family support services: What can be learned from research on help-seeking? A review. Child and Family Social Work, 8, 341-350. http://dx.doi.org/10.1046/j.1365-2206.2003.00289.x

Denov, M. (2004). The long-term effects of child sexual abuse by female perpetrators: Aqualitative study of male and female victims. Journal of Interpersonal Violence, 19(10), 1137-1156. http://dx.doi.org/10.1177/0886260504269093

Dersch, C., \& Munsch, J. (1999). Male victims of sexual abuse: An analysis of substantiationof child protective services reports. Journal of Child Sexual Abuse, 8, 27-47. http://dx.doi.org/10.1300/J070v08n01_03

Du Mont, J., MacDonald, S., White, M., Turner, L., White, D., Kaplan, S., \& Smith, T. (2014). Client satisfaction with nursing-led sexual assault and domestic violence services in Ontario. $\begin{array}{llll}\text { Journal of } & \text { forensic nursing, } & 10(3), & 122-134 .\end{array}$ http://dx.doi.org/10.1097/JFN.0000000000000035

Easton, S. D. (2014). Masculine norms, disclosure, and childhood adversities predict long-term mental distress among men with histories of child sexual abuse. Child abuse \& neglect, 38(2), 243-251. http://dx.doi.org/10.1016/j.chiabu.2013.08.020

Easton, S. D., Coohey, C., Rhodes, A. M., \& Moorthy, M. V. (2013). Posttraumatic growth among men with histories of child sexual abuse. Child maltreatment, 18(4), 211-220. http://dx.doi.org/10.1177/1077559513503037

Easton, S. D., Renner, Lynette M., \& O’Leary, P. (2013). Suicide attempts among men with histories of child sexual abuse: Examining abuse severity, mental health, and masculine norms. Child Abuse \& Neglect, 380-387. http://dx.doi.org/10.1016/j.chiabu.2012.11.007

Easton, S. D., Saltzman, L. Y., \& Willis, D. G. (2014). "Would you tell under circumstances like that?" Barriers to disclosure of child sexual abuse for men. Psychology of Men \& Masculinity, 15(4), 460-469. http://dx.doi.org/10.1037/a0034223

Emslie C., Damian, R., Ziebland, S. \& Hunt, K. (2006). Men's accounts of depression:reconstructing or resisting hegemonic masculinity? Social Science \& Medicine, 62(9), 2246-2257. http://dx.doi.org/10.1016/j.socscimed.2005.10.017

Finkelhor, D., Turner, H. A., Shattuck, A., \& Hamby, S. L. (2013). Violence, crime, and abuse exposure in a national sample of children and youth: an update. JAMA pediatrics, 167(7), 
614-621. http://dx.doi.org/10.1001/jamapediatrics.2013.42

Fleming, V., Gaidys, U. \& Robb, V. (2003). Hermeneutic research in nursing: developing a Gadamerian-based research method. Nursing Inquiry, 10(2), 113-120. http://dx.doi.org/10.1046/j.1440-1800.2003.00163.x

Grossman, F., Sorsoli, L., \& Kia-Keating, M. (2006). A Gale Force Wind: Meaning Making by Male Survivors of Childhood Sexual Abuse. American Journal of Orthopsychiatry, 76(4), 434-443. http://dx.doi.org/10.1037/0002-9432.76.4.434

Gadamer, H. G., \& Silverman, H. J. (1991). Gadamer and hermeneutics. New York: Rutledge.

Gallo-Silver, L., Anderson, C. M., \& Romo, J. (2014). Best Clinical Practices for Male Adult Survivors of Childhood Sexual Abuse: "Do No Harm". The Permanente Journal, 18(3), 82. http://dx.doi.org/10.7812/TPP/14-009

Galloway, J., \& Sheridan, S. M. (1994). Implementing Scientific Practices Through CaseStudies: Examples Using Home-School Interventions and Consultation. Journal of School Psychology, 32(4), 385-413. http://dx.doi.org/10.1016/0022-4405(94)90035-3

Garfield, C. I. A., \& Rogers, T. (2008). A Review of Men's Health and Masculinity. American Journal of Lifestyle Medicine, 2, 474. http://dx.doi.org/10.1177/1559827608323213

Holmes, W. (2007). Men's childhood sexual abuse histories by one-parent versus two-parent status of childhood home. Journal of Epidemiology and Community Health, 61(4), 319-25. http://dx.doi.org/10.1136/jech.2005.040188

Holmes, G., Offen, L., \& Waller, G. (1997). See no evil, hear no evil, speak no evil: Why do relatively few male victims of childhood sexual abuse receive help for abuse-related issues in adulthood? Clinical Psychology Review, $\quad 17(1), \quad 69-88$. http://dx.doi.org/10.1016/S0272-7358(96)00047-5

Holmes, W., \& Slap, G. (1998). Sexual abuse of boys: Definition, prevalence, correlates,sequelae, and management. Journal of the American Medical Association, 280, 1855-1862. http://dx.doi.org/10.1001/jama.280.21.1855

Holz, K. (1994). A practical approach to clients who are survivors of childhood sexual abuse. Journal of Nurse-Midwifery, 39(1), 13-18. http://dx.doi.org/10.1016/0091-2182(94)90037-X

Hooper, C., \& Warwick, I. (2006). Gender and the politics of service provision for adults with a history of childhood sexual abuse. Critical Social Policy, 26, 467-479. http://dx.doi.org/10.1177/0261018306062596

Hovey, A., Stalker, C. A., Schachter, C. L., Teram, E., \& Lasiuk, G. (2011). Practical ways psychotherapy can support physical healthcare experiences for male survivors of childhood sexual abuse. Journal of child sexual abuse, 20(1), 37-57. http://dx.doi.org/10.1080/10538712.2011.539963

Kia-Keating, M., Grossman, F., Sorsoli, L., Epstein, M., \& Cochran, Sam V. (2005). Containing and Resisting Masculinity: Narratives of Renegotiation Among Resilient Male 
Survivors of Childhood Sexual Abuse. Psychology of Men \& Masculinity, 6(3), 169-185. http://dx.doi.org/10.1037/1524-9220.6.3.169

Kia-Keating, M., Sorsoli, L., \& Grossman, F. K. (2010). Relational challenges and recoveryprocesses in male survivors of childhood sexual abuse. Journal of Interpersonal Violence, 25(4), 666-83. http://dx.doi.org/10.1177/0886260509334411

Koch, T. (1999). An interpretative research process: Revisiting phenomenological and hermeneutical approaches. Nurse Researcher, 6, 20-34. http://dx.doi.org/10.7748/nr1999.04.6.3.20.c6085

Laaksonen, T., Sariola, H., Johansson, A., Jern, P., Varjonen, M., Von der Pahlen, \& Santtila, P. (2011). Changes in the prevalence of child sexual abuse, its risk factors, and their associations as a function of age cohort in a Finnish population sample. Child Abuse \& Neglect, 35(7), 480-490. http://dx.doi.org/10.1016/j.chiabu.2011.03.004

MacMillan, H. L., Fleming, J. E., Streiner, D. L., Lin, E., Boyle, M. H., Jamieson, E., ... Beardslee, W. R. (2001). Childhood abuse and lifetime psychopathology in a community sample. American Journal of Psychiatry, 158(11), 1878-83. http://dx.doi.org/10.1176/appi.ajp.158.11.1878

Matthew, L., (2002). Where Angels Fear: Ritual Abuse in Scotland. Dundee: Dundee Young Women's Centre (Trading) Limited.

McClintock, C. C., Brannon, D., \& Maynard-Moody, S. (1979). Applying the logic of sample surveys to qualitative case studies: The case cluster method. Administrative Science Quarterly, 612-629. http://dx.doi.org/10.2307/2392367

Mein, J., Palmer, C., Shand, M., Templeton, J., Parekh, V., Mobbs, M., ... Young, L. (2003). Management of acute adult sexual assault. Medical Journal of Australia, 178(5), 226-230.

Mendel, M. (1995). The male survivor: The impact of sexual abuse. London: Sage. http://dx.doi.org/10.4135/9781483327044

Meyer, C. B. (2001). A case in case study methodology. Field methods, 13(4), 329-352. http://dx.doi.org/10.1177/1525822X0101300402

Moody, C. (1999). Male child sexual abuse. Journal of Pediatric Health Care, 13(3), 112-9. http://dx.doi.org/10.1016/S0891-5245(99)90072-X

Neame, A., \& Heenan, M. (2003). What Lies Behind the Hidden Figure of Sexual Assault? Issue of Prevalence and Disclosure. Australian Centre for the Study of Sexual Assault Briefing, 1, 1-15.

Nelson, S. (2009). Care and Support Needs of Men Who Survived Childhood Sexual Abuse: Report of a Qualitative Research Project. Centre for Research on Families and Relationships: Edinburgh.

O'Leary, P., \& Gould, N. (2009). Men who were sexually abused in childhood and subsequent suicidal ideation: Community comparison explanations and practice implications. 


\section{Macrothink}

International Journal of Social Work

ISSN 2332-7278 2016, Vol. 3, No. 1

Journal of British Social Work, 39, 950-968. http://dx.doi.org/10.1093/bjsw/bcn130

Paine, M., \& Hansen, D. (2002). Factors influencing children to self-disclose sexual abuse. Clinical Psychology Review, 22(2), 271-295. http://dx.doi.org/10.1016/S0272-7358(01)00091-5

Pérez-Fuentes, G., Olfson, M., Villegas, L., Morcillo, C., Wang, S., \& Blanco, C. (2013). Prevalence and correlates of child sexual abuse: a national study. Comprehensive psychiatry, 54(1), 16-27. http://dx.doi.org/10.1016/j.comppsych.2012.05.010

Preininger, D., \& Rapmund, V. (2008). Indirect aggression: A personal journey amidst socialConfusion (Unpublished Master's Thesis). University of South Africa.

Scottish Government. (2014) National Guidance for child protection in Scotland. Edinburgh:Scottish Government.

Sigurdardottir, S., Halldorsdottir, S., \& Bender, S. (2012). Deep and almost unbearable suffering: Consequences of childhood sexual abuse for men's health and well - being. $\begin{array}{llll}\text { Scandinavian Journal of Caring } & \text { 688-697. }\end{array}$ http://dx.doi.org/10.1111/j.1471-6712.2012.00981.x

Spataro, J., Moss, S. \& Wells, D. (2001). Child sexual abuse: A reality for both sexes. Australian Psychologist, 36(3), 177-183. http://dx.doi.org/10.1080/00050060108259653

Teram, E., Stalker, C., Hovey, A., Schachter, C., \& Lasiuk, G. (2006). Towards malecentriccommunication: Sensitizing health professionals to the realities of male childhood sexual abuse survivors. Issues in Mental Health Nursing, 27, 499-517. http://dx.doi.org/10.1080/01612840600599994

Willis, D. G., Zucchero, T. L., DeSanto-Madeya, S., Ross, R., Leone, D., Kaubris, S., ... Easton, S. D. (2014). Dwelling in Suffering: Barriers to Men's Healing from Childhood Maltreatment. Issues in mental health nursing, 35(8), 569-579. http://dx.doi.org/10.3109/01612840.2013.856972

Yin, R. K. (2013). Case study research: Design and methods. Sage publications.

\section{Copyright Disclaimer}

Copyright reserved by the author(s).

This article is an open-access article distributed under the terms and conditions of the Creative Commons Attribution license (http://creativecommons.org/licenses/by/3.0/). 